\title{
Diversidad de hongos micorrízicos arbusculares asociados a plantas voluntarias de maíz en suelos de transición: ecosistema natural - uso agrícola
}

\section{Diversity of arbuscular mycorrhizal fungi associated to volunteer maize plants in transition soils: natural ecosystem - agricultural use}

\author{
Rocío Guadalupe Cervantes-Gámez 1, a, Ofelda Peñuelas-Rubio 2, a , Nathali Araujo-Benard ${ }^{3,4}$, Rosario Alicia Fierro- \\ Coronado ${ }^{3}$, Dora Trejo-Aguilar ${ }^{5}$, Ignacio Eduardo Maldonado-Mendoza ${ }^{3}$, Jesús Damián Cordero-Ramírez ${ }^{4}$

\begin{abstract}
${ }^{1}$ Departamento de Estudios para el Desarrollo Sustentable de Zonas Costeras, Centro Universitario de la Costa Sur, Universidad de Guadalajara, Autlán, Jalisco, México. ${ }^{2}$ Departamento de Ingenierías, Tecnológico Nacional de México/Instituto Tecnológico del Valle del Yaqui, Bácum, Sonora, México. ${ }^{3}$ Departamento de Biotecnología Agrícola, CIIDIR-Unidad Sinaloa, Instituto Politécnico Nacional, Guasave, Sinaloa, México. ${ }^{4}$ Departamento de Ciencias Naturales y Exactas, Universidad Autónoma de Occidente, Unidad Regional Guasave. Guasave, Sinaloa, México. ${ }^{5}$ Facultad de Ciencias Agrícolas, Universidad Veracruzana, Xalapa, Veracruz, México. a Las dos autoras contribuyeron con la misma cantidad de trabajo al manuscrito por lo que ambas se consideran como primeras
\end{abstract} \\ autoras.
}

\section{RESUMEN}

Antecedentes: Las plantas voluntarias se consideran un problema en suelos de cultivo como posible reservorio de enfermedades, pero también de diversidad de microorganismos. Plantas micotróficas como el maíz permitirían preservar inóculos micorrízicos. La zona de preservación ecológica La Uba, en Guasave, Sinaloa, es un relicto de vegetación de selva baja caducifolia y su microbiota ha sido poco estudiada. Esta región ha sido reconvertida a suelo agrícola, por lo que estudiamos una zona de transición aledaña.

Objetivo: Establecer la diversidad de hongos micorrízicos arbusculares (HMA) presentes en rizósfera y raíces de plantas voluntarias de maíz en una zona de transición contigua a La Uba.

Métodos: Se colectaron raíces de maíz de plantas voluntarias y suelo una vez, entre ciclos agrícolas en una zona de transición. Se extrajo ADN genómico de raíces colonizadas con HMA y esporas del suelo, se amplificó y se secuenció masivamente el ITS del ADN ribosomal.

Resultados y conclusiones: Se encontraron un total de 12 especies de HMA, pertenecientes a los géneros Glomus, Rhizophagus, Funneliformis y Gigaspora; siendo Glomus el más abundante. Glomus indicum se reporta por primera vez en México. Las plantas voluntarias de maíz pueden servir como reservorio de inóculo de HMA en suelos agrícolas.

Palabras clave: HMA, Glomeromycota, Zea mays, selva baja caducifolia, cambio de uso de suelo

\section{ABSTRACT}

Background: Volunteer plants have been considered as a problem in crop areas as a possible disease reservoir, but also of microorganism diversity. Mycotrophic plants, such as maize may allow preserving mycorrhizal inoculum. The ecological preservation area La Uba, in Guasave, Sinaloa, is a relictual area of vegetation of low deciduous forest and studies of its soil microbiota are scarce. This region has been recently converted to agricultural soils. This is why we studied a contiguous transition zone.

Objective: To establish the diversity of arbuscular mycorrhizal fungi (AMF) present in the rhizosphere and roots of volunteer maize plants in the transition zone contiguous to La Uba.

Methods: Volunteer maize roots and soil were collected once in between agricultural cycles in a transition zone. Genomic DNA was extracted from AMF colonized maize roots and soil spores; the ITS region of the ribosomal DNA was amplified and massively sequenced.

Results and conclusions: A total of twelve species of AMF were found, belonging to the genera Glomus, Rhizophagus, Funneliformis y Gigaspora.; Glomus was the most abundant genus. Glomus indicum was reported for the first time in Mexico. Volunteer maize plants may assist in conserving AMF inoculum in crop soils.

Keywords: AMF, Glomeromycota, Zea mays, low deciduous forest, change of soil use

\section{ARTICLE HISTORY}

Received 30 July 2020 / Accepted 08 December 2020

Published on line: 10 April 2021
CORRESPONDING AUTHOR

\u Jesús Damián Cordero-Ramírez, elcofra@yahoo.com.mx ORCID: 0000-0002-8755-4828. 


\section{INTRODUCCIÓN}

Los sitios naturales conservados son de importancia ecológica, porque ahí se mantienen relictos de vegetación endémica. Estas áreas son reservorios de microorganismos de la rizósfera, indispensables para la sobrevivencia de las comunidades vegetales (Barois et al., 2009). En el valle de Guasave, Sinaloa, la vegetación natural es escasa, debido a que la mayor superficie del suelo, es utilizada para labores agrícolas (200,000 ha), y solo existe una zona conservada, que abarca 17.9 ha, decretada como Zona de Preservación Ecológica (ZPE) de Centro de Población "La Uba" (H. Ayuntamiento de Guasave, 1998) y la cual se considera un relicto de vegetación riparia y de selva baja caducifolia.

En el área de transición circundante a la ZPE se ha establecido cultivo de maíz (Zea mays), bajo el esquema de monocultivo intensivo, más de 500,000 ha cada año en Sinaloa (SIAP, 2020). Diversos reportes señalan que los sitios sometidos al monocultivo por muchos años, son susceptibles a la pérdida de la diversidad biológica del suelo (Trejo-Aguilar et al., 2013; Li et al., 2020).

La microbiota del suelo es un recurso natural fundamental en la fertilidad de los suelos, debido a la presencia de esta diversidad de microrganismos, las condiciones edáficas se mantienen y permiten la sobrevivencia de muchas especies vegetales. Entre estos destacan los hongos micorrízicos arbusculares (HMA) que forman una asociación entre las hifas del hongo y las raíces de más del $80 \%$ de las especies vegetales terrestres (Smith y Smith, 2008), donde la planta hospedera recibe nutrientes minerales y un aumento en la tolerancia a estrés de tipo biótico y abiótico (Smith y Read, 2008; Jung et al., 2012; Chen et al., 2017).

El maíz es una planta altamente micotrófica que se asocia con los HMA, pero debido a la producción intensiva o uso de variedades mejoradas, puede propiciar la selección de especies de hongos micorrízicos poco eficientes o disminuir su diversidad (Oehl et al., 2003; Sangabriel-Conde et al., 2015). En Sinaloa, el ciclo agrícola de esta gramínea es de otoño-invierno, por lo que el período de descanso agrícola suele abarcar de abril-mayo a noviembre-diciembre. Debido a la falta de agua para este cultivo, el cual es altamente demandante, cada vez se siembra con menor frecuencia en el período primavera-verano. Durante los periodos de descanso agrícola, las malezas que colonizan los campos agrícolas son de tipo ruderal y pertenecen a familias que comprenden plantas no-micotróficas, como Chenopodiaceae y Brassicaceae (Harley y Harley, 1987; Brundrett et al., 2002; Wang y Qiu, 2006). Los HMA han demostrado tener un efecto negativo sobre el crecimiento de diferentes especies de malezas (Rinaudo et al., 2010). Este efecto perjudicial sobre las malezas es amplificado en presencia de plantas de cultivo como ha sido mostrado en presencia de girasol (Rinaudo et al., 2010) y de maíz (Veiga et al., 2011). La disminución de cobertura vegetal durante dichos períodos de descanso en el monocultivo de maíz (Feldmann y Boyle, 1999) y en algunos casos el empleo de estrategias de manejo en ciclos consecutivos agrícolas, disminuyen el número de propágulos de HMA (Li et al., 2007). Sin embargo, en algunos casos se detecta la presencia de "plantas voluntarias", que son aquellas plantas de cualquier especie que germinan y se desarrollan por sí mismas entre los ciclos agrícolas, sin que hayan sido plantadas por los agricultores, a partir de restos de la siembra anterior, por dispersión por aves o viento. Generalmente han sido consideradas como un problema para la agricultura, debido a que éstas extraen nutrientes del suelo y representan un reservorio de agentes causales de enfermedades (Moura et al., 2020), por lo que desde el punto de vista agronómico no son deseables. Sin embargo, éstas representan una alternativa importante para la sobrevivencia de los hongos micorrízicos, debido a que durante los periodos de descanso entre cultivos, la densidad de propágulos tiende a disminuir (Li et al., 2007; Wang et al., 2020). Esta disminución de propágulos de HMA se lleva a cabo en los sistemas de cultivo intensivos con barbecho (períodos de descanso entre ciclos de cultivo) no solo por el período mismo, sino por las diferentes estrategias de manejo del suelo, las cuales incluyen la remoción de residuos vegetales, aplicación de herbicidas químicos, y el rastreo que implica la ruptura de redes de micelio presentes en el suelo (Meza-Ponce y Angulo-Santos, 2011) y en algunas ocasiones inclusive la quema de soca. Aunado a esta problemática, la cual probablemente contribuya a la disminución de la diversidad de HMA y número de propágulos, existen otros factores de selección biológica que también contribuyen a esta disminución. Estos incluyen la reducción de la diversidad determinado por la interacción de los HMA con el monocultivo de maíz por ciclos consecutivos, 
sin que se roten otros cultivos (Thougnon et al., 2014; Zhang et al., 2020). La diversidad genética y funcional de los géneros y especies de HMA (Bever et al., 2001; Helgason y Fitter, 2009) asociados con la misma especie huésped pueden presentar diferencias relacionadas con la capacidad de esporulación (Bever, 2002) y de colonización (Smith et al., 2000; Hao et al., 2008). Desafortunadamente, poco se sabe sobre la función de las plantas voluntarias, pues existen escasos estudios sobre el papel que éstas pueden tener en la población de HMA presentes en los suelos agrícolas. En México, se ha reportado la presencia de los HMA en casi todos los ecosistemas (Camargo-Ricalde et al., 2012). Martínez-Álvarez (2003) realizó un estudio de los HMA presentes en suelos de La Uba y suelos agrícolas, mediante la clasificación morfológica de las esporas y técnicas de PCR, clonación y secuenciación de diferentes regiones del ADNr, generando un banco de germoplasma regional de esporas de HMA. Sin embargo, las técnicas moleculares empleadas en ese estudio solo permitieron la identificación de dos especies Glomus versiforme y $G$. intraradices (actualmente Rhizophagus intraradices). Por otra parte, la identificación morfológica mostró la presencia de morfotipos de los géneros Gigaspora y Scutellospora. Actualmente las técnicas de biología molecular permiten conocer con mayor especificidad la ubicación taxonómica de estos hongos, mediante el uso de oligonucleótidos diseñados exclusivamente para los géneros y especies de HMA (Souza, 2015), y la secuenciación masiva que permite una mayor aproximación a la diversidad completa en una muestra. Por lo anterior, el objetivo del presente trabajo se centró en identificar el ensamble de HMA asociados a rizósfera y raíces de plantas voluntarias de maíz creciendo entre ciclos de cultivo en la zona de transición de la ZPE La Uba, Guasave, Sinaloa.

\section{MATERIALES Y MÉTODOS}

\section{Sitio de muestreo}

El muestreo se realizó el 24 de agosto de 2017 en un área convertida a terreno agrícola (desde hace diez años), de la zona de transición de la ZPE La Uba, ubicada en el ejido La Cofradía, Guasave, Sinaloa. Dicha ZPE comprende una superficie de 17.9 ha. El sitio de muestreo para este trabajo está ubicado en las coordenadas geográficas $25^{\circ} 29^{\prime} 04.5^{\prime \prime}$ latitud Norte y $108^{\circ}$
28 '03.0" longitud Oeste. Las muestras se tomaron de tres puntos diferentes de una sola parcela (4 ha), ubicándolos con la siguiente referencia: Norte (N), Centro (C) y Sur (S) (Figura 1). Durante la época de descanso del cultivo de maíz (junio a noviembre para esta parcela), en cada punto, se ubicaron plantas voluntarias de maíz de aproximadamente 40 a 60 días post-emergencia (etapas fenológicas vegetativa V4 a floración R1) y se colectaron cinco muestras de raíces y suelo a $30 \mathrm{~cm}$ de profundidad empleando una pala y recogiendo un mínimo de $1 \mathrm{~kg}$ de suelo. Las muestras se trasladaron al Laboratorio de Ecología Molecular de la Rizósfera del Centro Interdisciplinario de Investigación para el Desarrollo Integral Regional del Instituto Politécnico Nacional (CIIDIR, Unidad Sinaloa) para su procesamiento. En esta región, el período de descanso agrícola incluye el período del verano comprendido dentro de la época de lluvias que ocurre de julio a octubre, y adicionalmente en los meses de noviembre a enero se pueden presentar lluvias intermitentes $(H$. Ayuntamiento de Guasave, 1998). Las plantas voluntarias de maíz surgen dos a tres semanas después de la cosecha y limpieza del terreno, por lo tanto, se estimó que las plantas colectadas tuvieran entre 40 y 60 días post-emergencia. Estas plantas son retiradas por la maquinaria agrícola que realiza las labores de rastreo y preparación de surcos previo a la siembra de la parcela.

\section{Análisis de la composición del suelo}

El análisis físico-químico de suelo se realizó en el laboratorio de Nutrición Vegetal del CIIDIR Sinaloa. Se tomaron $500 \mathrm{~g}$ de una muestra compuesta por las cinco muestras tomadas por punto dentro de la parcela y se tamizaron con una malla de $>5 \mathrm{~mm}$. La acidez $(\mathrm{pH})$ y la conductividad eléctrica (CE) se determinaron en el extracto de pasta saturada, en relación 1:5 suelo-agua, las mediciones se obtuvieron con un potenciómetro Orion Modelo 230A calibrado a pH 4.0 y 7.0, y a $1.4118 \mathrm{dE} / \mathrm{m}$ para CE. El fósforo extraíble total se obtuvo por el método de Olsen, utilizando un espectrofotómetro Thermospectronic UV-Visible Genesys. Los cationes intercambiables ( $\mathrm{Ca}, \mathrm{Mg}, \mathrm{Na}$ y $\mathrm{K}$ ) se midieron por el método de acetato de amonio. La materia orgánica se midió con el método de Walkley y Black (Jackson, 1964). Los nitratos fueron cuantificados mediante un método colorimétrico para este tipo de nutrientes, siguiendo las indicaciones del fabricante (Marca Merck Millipore, No. Cat. 11020. Naucalpan de 


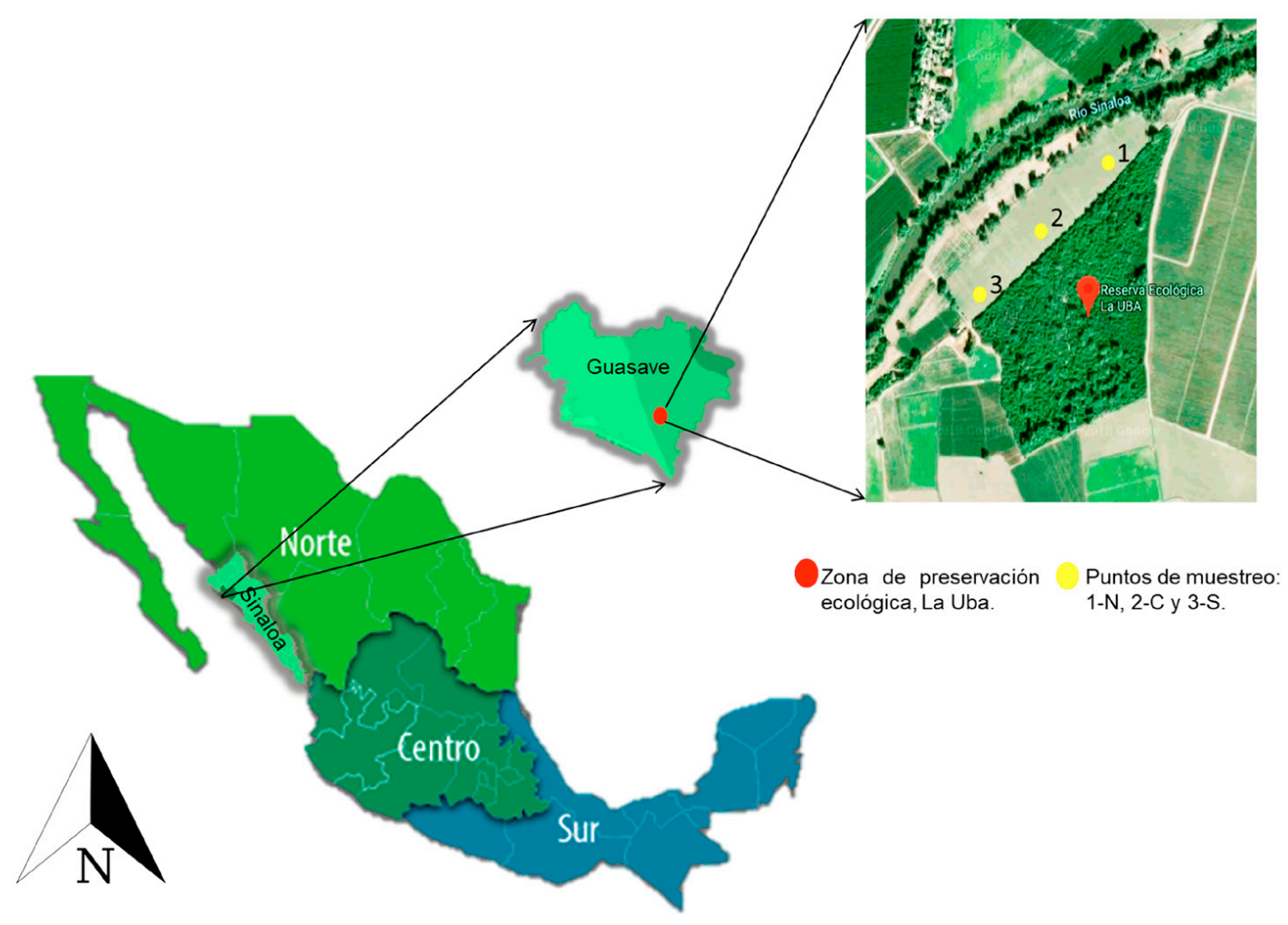

Figura 1. Mapa del sitio de muestreo, ZPE la Uba, Guasave, Sinaloa. En los puntos de muestreo N indica norte, C centro y S sur.

Juárez, Estado de México, México). Para medir la concentración de micronutrimentos ( $\mathrm{Fe}, \mathrm{Mn}, \mathrm{Zn}$ y $\mathrm{Cu}$ ) se utilizó el método AS-14 de la norma oficial mexicana NOM-021-RECNAT-2000 (2002).

\section{Aislamiento y conteo de esporas de suelo}

El suelo de la rizósfera de las cinco muestras de cada sitio, fue homogenizado como una sola. De las muestras compuestas (provenientes de los sitios Norte, Centro y Sur) se tomaron ocho réplicas de $50 \mathrm{~g}$. Cada una de estas, fue tratada por separado, se hidrataron con agua destilada (proporción 1:3 peso/volumen) y se procesaron de acuerdo al método de tamizado en húmedo (Brundrett et al., 1996) utilizando tamices de 250, 100 y 53 um de luz de malla.

Para la separación de las esporas, se utilizó la metodología de extracción en húmedo y centrifugación en un gradiente de sacarosa (Sieverding, 1991). Cada réplica se lavó a través de una tela de nylon de $53 \mu \mathrm{m}$ de poro con abundante agua destilada y posteriormente se revisó sobre una caja Petri bajo el estereoscopio (Marca Faga-Lab, modelo C2M4, No. Cat. ST 6024-B1) con el objetivo 4X. Con un pincel (Marca ROSS 2/0, mo- delo 436 México) se seleccionaron las esporas viables y se realizó el conteo de las mismas, los resultados se expresaron en esporas por $\mathrm{kg}$ de suelo. Las esporas fueron conservadas a $4{ }^{\circ} \mathrm{C}$ en agua destilada para su posterior análisis molecular.

\section{Obtención de raíces y eficiencia de colonización micorrízica}

La obtención y procesado de las raíces consistió en cortar el sistema radical de cada planta desde la base del tallo (cinco plantas por sitio, 15 plantas en total), posteriormente se aplicaron tres lavados con agua corriente. El sistema radical de cada planta se dividió en dos secciones, una de éstas se utilizó para determinar el porcentaje de colonización; de la segunda se separaron las raíces secundarias para ser molidas en nitrógeno líquido y posteriormente utilizarlas para la extracción de ADN genómico. Las raíces pulverizadas fueron conservadas a $-80^{\circ} \mathrm{C}$ hasta su posterior uso. El porcentaje de colonización micorrízica se determinó por el método de clareo y tinción de Phillips y Hayman (1970) y la cuantificación de estructuras internas se evaluó empleando un microscopio óptico, mediante la técnica de McGonigle et al. (1990). 
Extracción del ADN genómico

Dada la baja cantidad de esporas obtenidas, se decidió conjuntar una sola muestra compuesta de los tres sitios muestreados, a partir de la cual se realizó la extracción del ADN genómico, utilizando DNAzol® (Genomic DNA Isolation Reagent, No. Cat. 10503027). Para la extracción a partir de muestras de raíces se utilizó el kit DNeasy plant mini kit (QIAgen, No. Cat. 69106) siguiendo las instrucciones del fabricante. Para la cuantificación del ADN se empleó el fluorómetro QubitTM (Marca Invitrogen, No. Cat. Q32857).

\section{PCR anidada para amplificar especies de Glomeromycotina}

Por separado, se realizó una PCR anidada de cada muestra de raíces y esporas en un termociclador MultiGeneTM. Para la primera PCR se emplearon los sets de oligonucleótidos SSUAf1-2 y LSUmAr1-4 de acuerdo a lo reportado por Krüger et al. (2009) con los cuales se obtuvo un amplicón de 1.8 kb, que sirvió de templado para la segunda amplificación con los sets de oligonucleótidos SSUmCf1-2 y LSUmBr1-5 (1.5kb). Se realizó una última amplificación a partir de los amplicones obtenidos en la PCR anidada empleando los primers ITS1 e ITS4 (White et al., 1990) modificados en sus extremos con una secuencia como etiqueta para permitir la generación de amplicones compatibles con la plataforma de secuenciación (Illumina Mi-Seq). Las secuencias de estos oligonucleótidos fueron: ITS1 Mi-Seq: 5' TCG TCG GCA GCG TCA GAT GTG TAT AAG AGA CAG TCC GTA GGT GAA CCT GCG G 3'; ITS4 Mi-Seq: 5' GTC TCG TGG GCT CGG AGA TGT GTA TAA GAG ACA GTC CTC CGC TTA TTG ATA TGC 3'. El amplicón obtenido fue de $\sim 500 \mathrm{pb}$.

\section{Visualización y purificación de los productos de PCR}

Los productos de PCR fueron corridos en agarosa al 1 \% utilizando buffer TAE 0.5X. Para la purificación del producto de PCR se utilizó el kit QIAquick PCR purification (QIAgen, No. Cat. 12500-50) siguiendo las indicaciones del fabricante. El producto de PCR purificado se cuantificó en un espectrofotómetro NanoDrop 2000 (Marca Thermo Fisher Scientific, No. Cat. PRD-03546).

\section{Análisis de secuencias}

Los amplicones finales purificados fueron enviados al Laboratorio Nacional de Genómica para la Biodiversidad (LANGEBIO) para ser secuenciados en el sistema MiSeq de Illumina en el formato paired-end (2×300).
Cada secuencia se comparó con la base de datos de The Ribosomal Database Project (RDP; https://rdp. cme.msu.edu/); utilizando herramientas de clasificación jerárquica para cada muestra. Se limitó a separar de acuerdo al etiquetado y se clasificaron las secuencias por jerarquía, se realizó un análisis estadístico básico para generar un reporte por muestra y los archivos correspondientes a cada uno de los metagrupos y de los subgrupos detectados.

Análisis de diversidad

La diversidad alfa se calculó mediante el índice alfa de Fisher, utilizando el software Past (PAleontological STatistics Version 3.25), con una matriz de datos de abundancia de especies por muestra de cada sitio.

\section{RESULTADOS Y DISCUSIÓN}

\section{Cuantificación de esporas y porcentaje de colonización}

Las esporas viables se encontraron en 160 4.36, 346 2.08 y 3474.16 esporas/kg de suelo en los puntos Norte, Centro y Sur, respectivamente. La muestra del punto Norte es la que mostró un número menor de esporas, comparada a los puntos Centro y Sur. La distancia a la zona de preservación ecológica es la misma y tampoco encontramos diferencias significativas en los parámetros fisicoquímicos de suelo en esta muestra comparado a los otros dos puntos de muestreo (Tabla 1) por lo que proponemos que esta variación es intrínseca al sitio muestreado. Las esporas de HMA pueden distribuirse heterogéneamente en un campo de cultivo (St. John y Koske, 1988) y su número puede no estar relacionado incluso con la distribución de raíces (Friese y Koske, 1991). Aun cuando existen pocos estudios para determinar el esfuerzo de muestreo para especies de HMA que esporulan en un campo agrícola, un estudio demostró que solo siete muestras de suelos agrícolas en Pensilvania, EUA son suficientes para analizar toda la diversidad de especies (Franke-Snyder et al., 2001). Aunque en nuestro caso se muestrearon tres puntos, estos representan muestras mezcladas de cinco plantas en el campo agrícola, por lo que sugerimos que con 15 muestras estamos estudiando la diversidad de especies de HMA del lote. Los valores en número de esporas son considerablemente bajos (de 8 a 17.35 esporas en 50 $\mathrm{g}$ de suelo, normalizado a $50 \mathrm{~g}$ de suelo), en comparación con un trabajo reportado para suelos donde se ha cultivado maíz (175 a 300 esporas en 50 g de suelo; 
Londoño et al., 2020). Otro trabajo, realizado por Oehl et al. (2003) mostró que la población de esporas en monocultivos de maíz puede oscilar entre 125 y 400 esporas en $50 \mathrm{~g}$ de suelo. Reportes previos indican que la abundancia de esporas es baja en suelos agrícolas con respecto a suelos de ambientes naturales (Trejo et al., 2016) y que a medida que la actividad agrícola se incrementa, la abundancia de HMA disminuye (Oehl et al., 2003, 2004). Nuestros resultados en cuanto a la baja disponibilidad de esporas encontrada en el presente estudio sugieren que es posible que la abundancia natural de esporas que existía en la reserva, ligado a la diversidad de especies vegetales antes del cambio de uso de suelo, se haya reducido en función de la interacción con las esporas del suelo que son afines a maíz. Zhang et al. (2020) evidenciaron como el monocultivo de maíz genera una menor diversidad de HMA, al comparar con lotes donde se desarrollan cultivos combinados de maíz y soya, lo cual fortalece la hipótesis de que a mayor tiempo realizando el monocultivo, la diversidad de HMA será menor. De este modo, en la zona de transición estudiada fueron seleccionados aquellos HMA que tienen mayor afinidad al cultivo, sobre todo después de un período de diez años de actividad agrícola sembrando maíz (Oehl et al., 2003).

Sin embargo, datos previos señalan que el número de esporas por kilogramo de suelo encontrado en el presente estudio (de 160 a 393) fue muy bajo comparado con lo reportado 15 años atrás, donde se obtuvieron de 1,200 a 4,100 esporas/kilogramo de suelo, en suelos asociados a otras especies vegetales incluyendo carrizo (Arundo donax L.), y sorgo (Shorgum halepense) muestreados en el interior de la ZPE La Uba (Martínez-Álvarez, 2003). Sin embargo, el estudio de Martínez-Álvarez (2003) también señala que los suelos agrícolas del norte de Sinaloa poseen cantidades muy altas de esporas $y$, de hecho, algunos muestran cantidades mayores de esporas que los suelos de la ZPE La Uba $(1,200-16,950$ esporas/kg de suelo). Otra explicación para la marcada diferencia en el número de esporas por kilogramo de suelo entre estos estudios, puede atribuirse a la etapa fenológica de la planta al momento del muestreo. Nuestras plantas eran jóvenes, de aproximadamente uno a dos meses de germinadas, por lo tanto, los HMA aún estaban colonizando activamente la planta y no en etapa de esporulación como ocurre en la etapa de madurez y senescencia del cultivo (Santos et al., 2007; Smith y Read, 2008) que es el caso de los muestreos realizados de suelo en el interior de la ZPE La Uba 15 años atrás. Todas las raíces de maíz analizadas presentaron estructuras fúngicas características de los HMA (arbúsculos, vesículas, hifas y esporas). El porcentaje de colonización osciló entre el 35.5 y el 48.4 \%. Estos porcentajes se consideran adecuados para la etapa fenológica en la que se encontraban las plantas cuando se realizaron los muestreos (Londoño et al., 2020).

Tabla 1. Análisis fisicoquímico de los tres sitios muestreados en la ZPE La Uba

\begin{tabular}{|c|c|c|c|c|}
\hline Parámetro fisicoquímicos & Sur & Centro & Norte & Referencia \\
\hline Potencial de hidrógeno $(\mathrm{pH})$ & 7.00 & 7.00 & 6.90 & 6.6.-7.3 (neutro) \\
\hline Conductividad eléctrica $\mathrm{CE}, \mathrm{mmhos} / \mathrm{cm}$ ) & 0.05 & 0.10 & 0.08 & $<2.0$ (despreciable) \\
\hline Materia orgánica (\%MO) & 0.75 & 0.75 & 0.73 & $<1.5$ (bajo) \\
\hline Nitratos (ppm NO$)_{3}$ ) & 50.00 & 50.00 & 50.00 & Medio \\
\hline Fósforo (mg/kg Olsen P) & 13.45 & 14.52 & 10.45 & $<10$ (bajo) \\
\hline Potasio (Cmol/kg P) & 1.33 & 1.35 & 1.30 & 0.9-1.75 (alto) \\
\hline Calcio (Cmol/kg Ca) & 18.90 & 10.60 & 22.90 & $14-20$ (alto) \\
\hline Magnesio (Cmol/kg Mg) & 3.90 & 2.90 & 2.90 & $>4.0$ (muy alto) \\
\hline Sodio (Cmol/kg Na) & 0.70 & 0.70 & 0.70 & $1.0-1.5$ (alto) \\
\hline Fierro $(\mathrm{Cmol} / \mathrm{kg} \mathrm{Fe})$ & 10.50 & 10.50 & 9.50 & $>9$ (adecuado) \\
\hline Cobre $(\mathrm{Cmol} / \mathrm{kg} \mathrm{Cu})$ & 7.70 & 8.00 & 7.70 & $>1-3$ (adecuado) \\
\hline Zinc (Cmol/kg Zn) & 2.10 & 3.10 & 2.18 & $>1.5$ (adecuado) \\
\hline Manganeso (Cmol/kg Mn) & 10.00 & 10.00 & 10.00 & >8 (adecuado) \\
\hline
\end{tabular}




\section{Identificación molecular}

Se lograron obtener más de 440,000 lecturas mediante secuenciación masiva, el 82 \% de éstas cumplieron con los criterios de calidad y longitud mínimas (Tabla 2). Más de 323,000 lecturas se alinearon con alguna secuencia reportada para el Phyllum Glomeromycota (73\%), de las cuales 269,336 se alinearon a nivel de género y 139,046 a nivel de especie. El análisis de la diversidad alfa sugiere que se identificó la totalidad de especies en el sitio de muestreo, es decir, la cantidad de lecturas que se alinean a taxa virtuales de HMA es representativa de la diversidad de las especies que co- lonizan raíces de plantas voluntarias de maíz (Figura 2). En el caso de las esporas, a pesar de haber obtenido una cantidad de lecturas equivalente al resto de los sitios, la cantidad de lecturas alineadas a taxa virtuales (especie) de HMA fue considerablemente menor (Tabla 2, Figura 2). A pesar de que se utilizaron varios $\mathrm{kg}$ de suelo para colectar esporas, la cantidad encontrada fue muy baja, y menor aun fue el número de esporas viables utilizadas para la extracción de ADN. Es probable que estas esporas estuvieran parasitadas por otros hongos, cuya similitud en la región amplificada no permitió discernir entre ellas a un nivel taxonómico inferior

Tabla 2. Conteo de lecturas (reads) obtenidas por secuenciación masiva y después del filtrado bioinformático, de acuerdo al origen de cada biblioteca

\begin{tabular}{cccccccc}
\hline & & & \multicolumn{3}{c}{ Mapeados } \\
\cline { 5 - 8 } Origen de la biblioteca & $\begin{array}{c}\text { Reads } \\
\text { iniciales }\end{array}$ & $\begin{array}{c}\text { Filtrados por } \\
\text { calidad }\end{array}$ & $\begin{array}{c}\text { Dominio } \\
\text { Fungi (ITS) }\end{array}$ & Phyllum & Género & Especie \\
\hline Raíces Sur & 111312 & 90798 & 89133 & 75542 & 66643 & 42115 \\
Raíces Centro & 69906 & 58808 & 57978 & 66117 & 57228 & 33802 \\
Raíces Norte & 130922 & 107842 & 106442 & 86920 & 79989 & 58875 \\
Esporas & 131062 & 109598 & 103885 & 95176 & 65476 & 4254 \\
Total & 443202 & 367046 & 357438 & 323755 & 269336 & 139046 \\
\hline
\end{tabular}

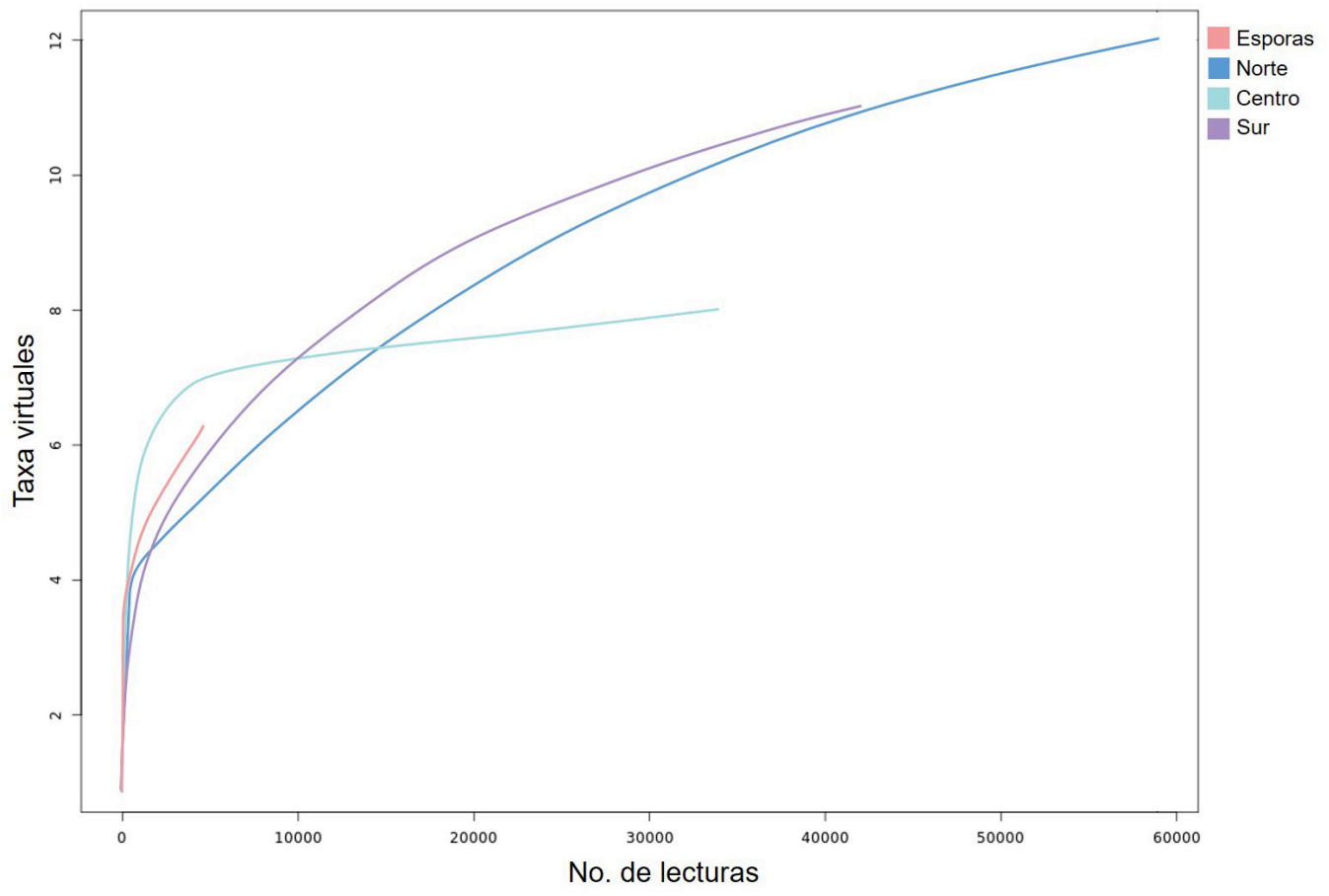

Figura 2. Curva de acumulación de especies en las muestras analizadas. Se indican la cantidad de taxa virtuales representados por número de lecturas, para cada uno de los sitios muestreados (norte, centro y sur) y esporas aisladas de la rizósfera de plantas voluntarias de maíz aledañas a la Zona de Preservación Ecológica La Uba, Guasave, Sinaloa. 
al de género. Sin embargo, consideramos que desde el punto de vista biológico el muestreo fue representativo, teniendo en cuenta los resultados obtenidos a partir de muestras de raíces, y debido a que no todas las especies de HMA asociadas a raíces esporulan (Trejo-Aguilar et al., 2013), así como a otros factores previamente mencionados que afectan la presencia de esporas viables en suelo.

\section{Incidencia y riqueza de especies}

De acuerdo al Catalogue of Life (2020-04-16 Beta, http://www.catalogueoflife.org/ consultado en junio 17 del 2020) se clasificaron e identificaron 12 taxa virtuales de HMA para el área de estudio (Figura 3). Sólo una especie estuvo presente en todas las muestras y réplicas analizadas, Glomus sp. 8. Ésta fue la especie de HMA más abundante en raíces (Figura 3B) y G. monosporum Gerd. \& Trappe (Figura 3C) fue la más abundante en esporas. Las 12 especies identificadas forman parte del orden Glomerales y pertenecen a la familia
Glomeraceae, principalmente representada por los géneros Glomus (G. indicum Błaszk., Wubet \& Harikumar, G. macrocarpum Tul. \& C. Tul., G. monosporum y Glomus sp. 8); Rhizophagus (R. aggregatus (N.C. Schenck \& G.S. Sm.) C. Walker, R. custos (C. Cano \& Dalpé) C. Walker \& A. Schüßler, R. irregularis (C. Cano \& Dalpé) C. Walker \& A. Schüßler, R. cf irregularis MUCL 43205 y 46240) y en menor proporción por especies del género Funneliformis (F. dimorphicus (Boyetchko \& J.P. Tewari) Oehl, G.A. Silva \& Sieverd. y F. mosseae (T.H. Nicolson \& Gerd.) C. Walker \& A. Schüßler) y Gigaspora (G. rosea T.H. Nicolson \& N.C. Schenck, Figuras 3 y 4). Cabe mencionar que los géneros Rhizophagus y Glomus solo pudieron identificarse en raíces colonizadas, pero no en esporas (Figura 4). Se identificaron cinco especies tanto en esporas como en raíces analizadas, estas fueron G. indicum, G. monosporum, Glomus sp. 8 , F. dimorphicus y F. mosseae. Las siete especies restantes, estaban presentes en las muestras de raíz, pero ausentes en las de esporas (Figura 3).

A)

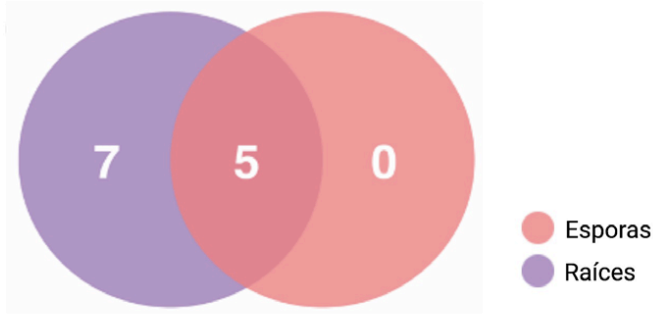

B)

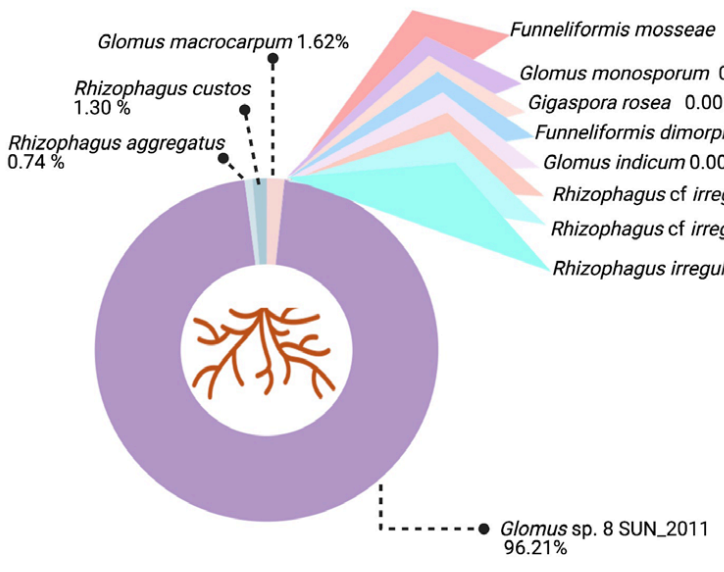

C)

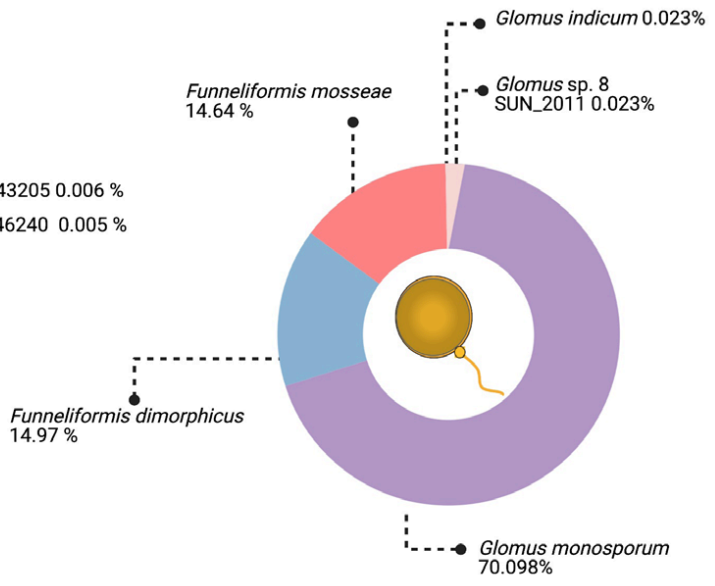

Figura 3. Especies de HMA en la rizósfera de plantas voluntarias de maíz en zona de transición de la ZPE La Uba. A: distribución de especies identificadas en raíces y esporas. Los números en la intersección de ambos círculos indican las especies compartidas (5) o presentes únicamente en raíces (7) o esporas (0). B: representación de la abundancia de cada especie de acuerdo a la cantidad de lecturas que le corresponden, muestras de raíces. C: muestras de esporas. 


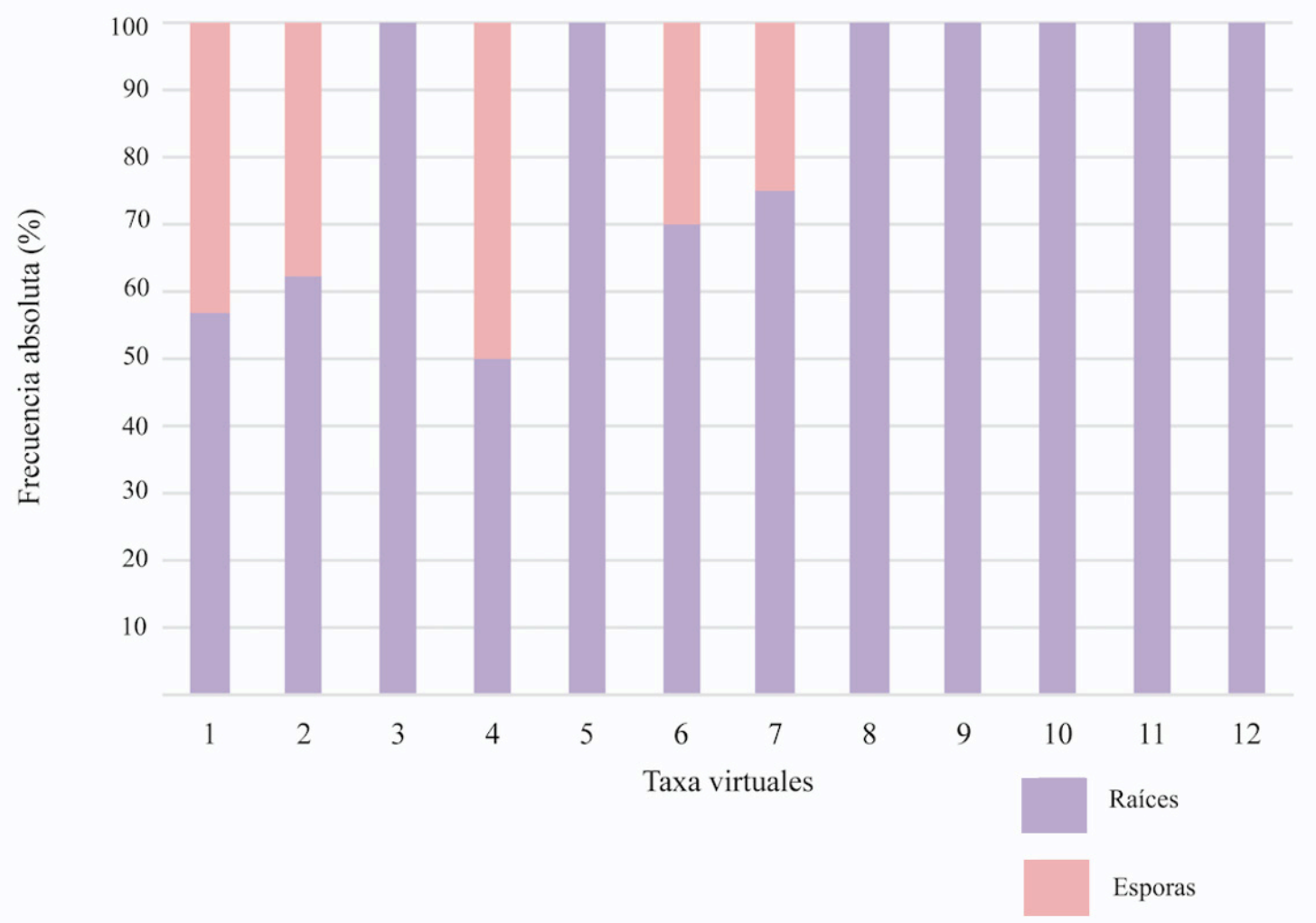

Figura 4. Frecuencia absoluta (\%) de las especies de HMA presentes en la rizósfera (raíces y suelo) de plantas de voluntarias de maíz. 1: Funneliformis dimorphicus. 2: F. mosseae. 3: Gigaspora rosea. 4: Glomus indicum. 5: G. macrocarpum. 6: G. monosporum. 7: Glomus sp. 8 SUN_2011. 8: Rhizophagus aggregatus. 9: Rhizophagus cf irregularis MUCL 43205. 10: R. cf irregularis MUCL 46240. 11. R. custos. 12: Rhizophagus irregularis.

Previamente, Martínez-Álvarez (2003) reportó la composición de esporas de HMA en suelos de la ZPE La Uba. En ese estudio se realizó la identificación a nivel de género con claves morfológicas y se reportaron morfotipos pertenecientes tanto a Glomus como a Gigaspora y a Scutellospora. La presencia de estos últimos dos géneros en esporas no pudo ser corroborado en el presente trabajo.

Un mayor número de especies pudo ser identificado a partir de muestras de raíz comparado con esporas por lo que la diversidad alfa fue mayor en raíces (4.36) respecto a esporas (2.39). Esta situación puede ser explicada por el bajo número de esporas viables recuperadas. Cabe resaltar que el muestreo se realizó en agosto del 2017, durante las lluvias de verano, y en un momento donde probablemente no existían las condiciones necesarias para que la producción de esporas fuera significativa, ya que la colonización aún se encontraba estableciéndose en el maíz de acuerdo a las etapas fenológicas en las cuales se encontraba (V4-R1). Otro factor que puede afectar la colonización y la esporulación pudiera ser la fertilización del cultivo, por ejemplo, cada ciclo de cultivo este lote se fertiliza con $180 \mathrm{~kg}$ por ha de gas amoníaco y, al mes y medio de cultivo se aplica otra dosis similar. Es posible que estos niveles de fertilización nitrogenada puedan ser inhibitorios de la esporulación (Wang et al., 2009). La observación de que la mayor parte de las esporas se encontraban rotas o parasitadas en las muestras analizadas sugiere que las condiciones climáticas lluviosas y las elevadas temperaturas que pueden alcanzarse en verano (por arriba de $40{ }^{\circ} \mathrm{C}$ ) favorezcan el micoparasitismo y expliquen el número tan bajo de esporas viables recuperado de las muestras.

Esto nos permitiría sugerir que las plantas voluntarias de maíz fungen como reservorio del inóculo y de la diversidad de HMA en el período inter-siembras, el cual es largo (abril/mayo a octubre/noviembre), entre los ciclos que corresponden a la primavera y verano cada año (Antoniolli et al., 2002).

Chagnon et al. (2013), mencionan que los HMA presentan diferentes habilidades competitivas y que es 
probable que los suelos agrícolas frecuentemente bajo labranza seleccionen hongos con estrategias ruderales (R). Estos hongos se caracterizan por tener un ciclo de vida corto, esporulación rápida y abundante, alta producción de micelio intraradical, tolerancia a la perturbación y pertenecen a la familia Glomeraceae, especificamente al género Glomus, son dominantes y se encuentran en suelos con baja diversidad (Maherali y Klironomos, 2012). Esto concuerda con nuestro trabajo, en donde encontramos once especies pertenecientes a la familia Glomeraceae y solo una a Gigasporaceae. Es importante comentar que se encontró una especie aun no caracterizada, Glomus sp. 8, que pudiera ser una especie nueva, muy abundante y que puede ser considerada "generalista". Los niveles de abundancia alcanzados por el género Glomus en el presente estudio fueron mayores comparados a lo reportado por Martínez-Álvarez (2003).

Cabe recalcar que F. dimorphicus solo ha sido reportada en una ocasión en México, en un ecosistema de bosque mesófilo de montaña (Peñuelas-Rubio et al., 2021) por lo que en este estudio por primera vez se indica su presencia en muestras de selva baja caducifolia. Adicionalmente, en este estudio se establece el primer reporte de la especie $G$. indicum en México. Por lo anterior, el número de registros de especies de Glomeromycota en México asciende de 143, como reportaron recientemente Varela et al. (2019), a 145 especies.

Al parecer, el maíz tiene preferencia por las especies de HMA pertenecientes a los géneros Glomus y Rhizophagus comparado con el resto de las especies, tanto en un híbrido de maíz blanco comercial como el del presente estudio, como en maíces criollos y un híbrido de maíz blanco nacional (Sangabriel-Conde et al., 2015). Cabe señalar que en el estudio de Sangabriel-Conde et al. (2015) en cinco variedades de maíz se encontraron 19 taxa virtuales y 65 más que fueron singletones (abundancia $\geq 2$ secuencias por taxon virtual). Por cada uno de los maíces se encontró de 10 a 38 taxa virtuales incluyendo las representadas por singletones. En el presente reporte encontramos 12 taxa virtuales y seis singletones (datos no mostrados), asociados a la rizósfera de las plantas voluntarias crecidas en suelos de cultivo de maíz blanco comercial, el mismo número que se reportó en maíz blanco híbrido Texcoco en dicho estudio (en ese estudio se incluyeron dos taxa tipo singleton).
En el presente estudio los singletones de una sola secuencia no fueron considerados para los análisis presentados en resultados y solo se incluyeron aquellos taxa representados por al menos dos secuencias. Los singletones de este trabajo representan cinco especies de la familia Glomeraceae (Claroideoglomus luteum (L.J. Kenn., J.C. Stutz \& J.B. Morton) C. Walker \& A. Schüßler, Glomus sp. 7, Oehlia diaphana (J.B. Morton \& C. Walker) Błaszk., Kozłowska, Niezgoda, B.T. Goto \& Dalpé [Syn. Rhizophagus diaphanus], R. intraradices (N.C. Schenck \& G.S. Sm.) C. Walker \& A. Schüßler y R. prolifer (Dalpé \& Declerck) C. Walker \& A. Schüßler) y una en la familia Ambisporaceae (Ambispora appendicula (Spain, Sieverd. \& N.C. Schenck) C. Walker).

Se ha encontrado que la presencia de HMA en la agricultura donde existe dependencia micorrízica es beneficiosa ya que ésta aumenta la productividad del cultivo (Nwaga et al., 2004). La captura y transferencia de nutrientes a la planta (Yao et al., 2001) son algunas de las ventajas que las caracterizan y ayudan a que el suelo sea productivo. Por ejemplo, los suelos de la Uba son muy productivos desde el punto de vista agrícola puesto que al estar al margen del río Sinaloa muestran una gran disponibilidad de materia orgánica entre otros nutrientes, pero estos elementos bajan su disponibilidad en el suelo debido a que son impactados por el manejo en forma de monocultivo en un sistema altamente intensivo, como sucede con el maíz.

Desafortunadamente, la creciente demanda de alimentos ha derivado en la conversión de suelos naturales a la agricultura, lo que indudablemente afecta la biodiversidad que reside en ellos. Sin embargo, gracias a este tipo de estudios nos podemos percatar que microorganismos como los HMA son capaces de subsistir a este cambio en la dinámica del suelo y algunas especies predominantes incluso pueden prevalecer después de varios años de actividad agrícola. Las plantas voluntarias juegan un papel importante facilitando la prevalencia de inóculo efectivo entre un ciclo agrícola y otro. Una vez más, es conveniente mencionar la importancia de que las prácticas agrícolas se desarrollen de manera más amigable con el ambiente, pudiendo aprovechar los beneficios que los HMA aportan a las plantas hospederas para el incremento de la producción y reducción de pérdidas por enfermedades. 


\section{AGRADECIMIENTOS}

OPR agradece a la convocatoria de Becas Nacionales Posdoctorales de CONACYT (2016-2017) que permitieron realizar una parte de este trabajo. JDCR agradece al Programa para el Desarrollo Profesional Docente, para el Tipo Superior (PRODEP), por proveer recursos parciales para este trabajo. El trabajo también fue financiado parcialmente por los proyectos de la Secretaría de Investigación y Posgrado del IPN (SIP 20181778 y SIP 20196353). RGCG agradece los aportes de Paul González en el diseño de las figuras.

\section{LITERATURA CITADA}

Antoniolli, Z., E. Facelli, P. O’Connor, D. Miller, K. Ophel-Keller, S. Smith, 2002. Spore communities of arbuscular mycorrhizal fungi and mycorrhizal associations in different ecosystems, South Australia. Revista Brasileira de Ciência do Solo 26: 627-635. Doi: 10.1590/S0100-06832002000300007

Barois, I., E.J. Huising, P. Okoth, D. Trejo, M. de los Santos, 2009. Below-ground biodiversity in Sierra Santa Marta, Los Tuxtlas, Veracruz, México. Instituto de Ecología, A.C., Xalapa.

Bever, J.D., 2002. Host-specificity of AM fungal population growth rates can generate feedback on plant growth. Plant and Soil 244: 281-290. Doi: 10.1023/A:1020221609080

Bever, J.D, P.A. Schultz, A. Pringle, J.B. Morton, 2001. Arbuscular mycorrhizal fungi: more diverse than meets the eye, and the ecological tale of why: The high diversity of ecologically distinct species of arbuscular mycorrhizal fungi within a single community has broad implications for plant ecology. BioScience 51: 923931. Doi: 10.1023/A:1020221609080

Brundrett, M., N. Bougher, B. Dell, T. Grove, N. Malajczuk, 1996. Working with mycorrhizas in forestry and agriculture. Australian Centre for International Agricultural Research, Canberra.

Brundrett, M.C., 2002. Coevolution of roots and mycorrhizas of land plants. New Phytologist 154: 275-304. Doi: 10.1046/j.14698137.2002.00397.x

Camargo-Ricalde, S.L, N.M Montaño, C.J. de la Rosa-Mera, S.A Montaño Arias, 2012. Micorrizas: una gran unión debajo del suelo. Revista Digital Universitaria 13: 3-19.

Chagnon, P.L., R.L. Bradley, H. Maherali, J.N. Klironomos, 2013. A trait-based framework to understand life history of mycorrhizal fungi. Trends in Plant Science 18: 484-491. Doi: 10.1016/j. tplants.2013.05.001

Chen J., H. Zhang, X. Zhang, M. Tang, 2017. Arbuscular mycorrhizal symbiosis alleviates salt stress in black locust through improved photosynthesis, water status, and $\mathrm{K}^{+} / \mathrm{Na}^{+}$homeostasis. Frontiers in Plant Science 8: 1739. Doi: 10.3389/fpls.2017.01739

Feldmann, F., C. Boyle, 1999. Weed mediated stability of arbuscular mycorrhizal effectiveness in maize monocultures. Journal of Applied Botanik-Angewandte Botanik, 73: 1-5.

Friese, C.F., R.E. Koske, 1991. The spatial dispersion of spores of vesicular-arbuscular mycorrhizal fungi in a sand dune: microscale patterns associated with the root architecture of American beachgrass. Mycological Research 95: 952-957. Doi: 10.1016/ S0953-7562(09)80092-0

H. Ayuntamiento de Guasave, 1998. "La Uba" Cofradía de Tamazula, Guasave. Zona de Preservación Ecológica de Centro de Pobla- ción. Sinaloa. H. Ayuntamiento de Guasave, Gobierno del Estado de Sinaloa, Secretaría de Desarrollo Social, Medio Ambiente y Pesca, Subsecretaría de Desarrollo Urbano y Ecológico, Dirección de Recursos Naturales y Medio Ambiente, Guasave.

Hao, L., J. Zhang., P. Christie, X. Li, 2008. Response of two maize inbred lines with contrasting phosphorus efficiency and root morphology to mycorrhizal colonization at different soil phosphorus supply levels. Journal of Plant Nutrition 31: 1059-1073. Doi: 10.1080/01904160802115227

Harley J.L., E.L. Harley, 1987. A checklist of mycorrhiza in the British flora. New Phytologist 105: 1-102. Doi: 10.1111/j.14698137.1987.tb00674.x

Helgason, T., A. Fitter, 2009. Natural selection and the evolutionary ecology of the arbuscular mycorrhizal fungi (Phylum Glomeromycota). Journal of Experimental Botany 60: 2465-2480. Doi: 10.1093/jxb/erp144

Jackson, M.L., 1964. Análisis químico de los suelos. Omega, Barcelona. Jung, S.C., A. Martínez-Medina, J.A. López-Ráez, M.J. Pozo, 2012. Mycorrhiza-induced resistance and priming of plant defenses. Journal of Chemical Ecology 38: 651-664. Doi: 10.1007/s10886012-0134-6

Krüger, M., H. Stockinger, C. Krüger, A. Schüssler, 2009. DNA-based species level detection of Glomeromycota: one PCR primer set for all arbuscular mycorrhizal fungi. New Phytologist 183: 212223. Doi : 10.1111/j.1469-8137.2009.02835.x

Li, L.F., Y. Zhang, Z.W. Zhao, 2007. Arbuscular mycorrhizal colonization and spore density across different land-use types in a hot and arid ecosystem, Southwest China. Journal of Plant Nutrition and Soil Science 170: 419-425. Doi: 10.1002/jpln.200625034

Li, X., K. Panke-Buisse, X. Yao, D. Coleman-Derr, C. Ding, X. Wang, H. Ruan, 2020. Peanut plant growth was altered by monocropping-associated microbial enrichment of rhizosphere microbiome. Plant and Soil 446: 655-669. Doi: 10.1007/s11104-01904379-1

Londoño, D.M.M., E. Meyer, K.J. da Silva, A.G. Hernández, R.D. de Armas, L.M. Soares, S.L. Stürmer, R.O. Nodari, C.R.F.S. Soares, P.E. Lovato, 2020. Root colonization and arbuscular mycorrhizal fungal community composition in a genetically modified maize, its non-modified isoline, and a landrace. Mycorrhiza 30: 611-621. Doi: 10.1007/s00572-020-00969-5

Maherali, H., J.N. Klironomos, 2012. Phylogenetic and trait-based assembly of arbuscular mycorrhizal fungal communities. PLOS ONE 7: e36695. Doi: 10.1371/journal.pone.0036695

Martínez-Álvarez, J.C., 2003. Identificación molecular de hongos micorrízicos arbusculares en el municipio de Guasave, Sinaloa. Tesis de Maestría. Centro Interdisciplinario de Investigación para el Desarrollo Integral Regional, Instituto Politécnico Nacional, México.

McGonigle, T.P., M.H. Miller, D.G. Evans, G.L. Fairchild, J.A. Swan, 1990. A new method which gives an objective measure of colonization of roots by vesicular-arbuscular mycorrhizal fungi. New Phytologist 115: 495-501. Doi: 10.1111/j.1469-8137.1990. tb00476.x

Meza-Ponce, R., J.R. Angulo-Santos, 2011. Producción de maíz blanco en la zona centro de Sinaloa. Colección Resultados de Proyectos, Fundación Produce Sinaloa, A.C., Culiacán. 
Moura, D.R., J.K. Yamada, L.C. de Albuquerque, N. de Carvalho Pontes, 2020. Crop rotation reduces the density of volunteer plants in processing tomato fields and the inoculum of bacterial spot. European Journal of Plant Pathology 156: 299-304. Doi: 10.1007/s10658-019-01868-y

NOM-021-RECNAT-2000 (Norma Oficial Mexicana), 2002. Que establece las especificaciones de fertilidad, salinidad y clasificación de suelos. Estudios, muestreo y análisis. SEMARNAT, México, D. F.

Nwaga, D., R. Ambassa-Kiki, E.L. Ngonkeu-Mangaptché, T. Chiegang, C. Megueni, 2004. Selection of arbuscular mycorrhizal fungi for inoculating maize and sorghum grown in oxisol / ultisol and vertisol in Camero on. In: Bationom A. (ed.), Managing nutrient cycles to sustain soil fertility in sub-Saharan Africa. Academy Science Publishers (ASP)/Tropical Soil Biology and Fertility Institute of CIAT, Nairobi.

Oehl, F., E. Sieverding, K. Ineichen, P. Mäder, T. Boller, A. Wiemken, 2003. Impact of land use intensity on the species diversity of arbuscular mycorrhizal fungi in agroecosystems of Central Europe. Applied and Environmental Microbiology 69: 2816-2824. Doi: 10.1128/AEM.69.5.2816-2824.2003

Oehl, F., E. Sieverding, P. Mäder, D. Dubois, K. Ineichen, T. Boller, A. Wiemken, 2004. Impact of long-term conventional and organic farming on the diversity of arbuscular mycorrhizal fungi. Oecologia 138: 574-583. Doi: 10.1007/s00442-003-1458-2

Peñuelas-Rubio, O., D. Trejo-Aguilar, R.G. Cervantes-Gámez, I.E. Maldonado-Mendoza, 2021. Análisis microbiómico de hongos micorrízicos arbusculares asociados a papaya, inoculada con consorcios de dos ecosistemas naturales. Scientia Fungorum 51:e1292. Doi: 10.33885/sf.2021.51.1292

Phillips, J.M., D.S. Haymann, 1970. Improved procedures for clearing roots and staining parasitic and vesicular-arbuscular mycorrhizal fungi for rapid assessment to infection. Transactions of the British Mycological Society 55: 158-161. Doi: 10.1016/S00071536(70)80110-3

Rinaudo, V., P. Bàrberi, M. Giovannetti, y M.G.A. van der Heijden, 2010. Mycorrhizal fungi suppress aggressive agricultural weeds. Plant and Soil 333: 7-20. Doi: 10.1007/s11104-009-0202-z

Sangabriel-Conde W., I.E. Maldonado-Mendoza, M.E. Mancera-López, J.D. Cordero-Ramírez, D. Trejo-Aguilar, S. Negrete-Yankelevich, 2015. Glomeromycota associated with Mexican native maize landraces in Los Tuxtlas, Mexico. Applied Soil Ecology 87: 63-71. Doi: 10.1016/j.apsoil.2014.10.017

Santos, J., R. Finlay, A. Tehler, 2007. Seasonal dynamics of arbuscular mycorrhizal fungal communities in roots in a seminatural grassland. Applied and Environmental Microbiology 73: 5613-5623. Doi: 10.1128/AEM.00262-07

SIAP, 2020. Avances de siembra y cosechas, resumen por Estado. Consultado el 25 de Junio del 2020. En: http://infosiap.siap. gob.mx:8080/agricola_siap_gobmx/ResumenProducto.do

Sieverding, E., 1991. Vesicular-arbuscular mycorrhiza management in tropical agrosystems. Schriftenreihe der Deutschen Gesellschaft für Technische Zusammenarbeit, Eschborn.

Smith, F.A., I. Jakobsen, S.E. Smith, 2000. Spatial differences in acquisition of soil phosphate between two arbuscular mycorrhizal fungi in symbiosis with Medicago truncatula. New Phytologist 147: 357-366. Doi: 10.1046/j.1469-8137.2000.00695.x

Smith, F.A., S.E. Smith, 2008. Structural diversity in (vesicular)-arbuscular mycorrhizal symbiosis. New Phytologist 137: 373-388. Doi: 10.1046/j.1469-8137.1997.00848.x

Smith, S.E., D.J. Read, 2008. Mycorrhizal symbiosis, Third Ed. Academic Press, London.

Souza, T., 2015. Handbook of arbuscular mycorrizhal fungi. Springer, Cham.

St. John, T.V., R.E. Koske, 1988. Statistical treatment of endogonaceous spore counts. Transactions of the British Mycological Society 91: 117-121. Doi: 10.1016/S0167-8809(99)00031-6

Thougnon-Islas, A.J., M. Eyherabide, H.E. Echeverria, H.R. SainzRozas, F. Covacevich, 2014. Mycotrophic capacity and efficiency of microbial consortia of arbuscular mycorrhizal fungi native of soils from Buenos Aires province under contrasting management. Revista Argentina de Microbiologia 46: 133-143. Doi: 10.1016/S0325-7541(14)70062-8

Trejo-Aguilar, D., L. Lara-Capistrán, I.E. Maldonado-Mendoza, R. Zulueta-Rodríguez, W. Sangabriel-Conde, M.E. Mancera-López, S. Negrete-Yankelevich, I. Barois, 2013. Loss of arbuscular mycorrhizal fungal diversity in trap cultures during long-term subculturing. IMA Fungus 4: 161-167. Doi: 10.5598/imafungus.2013.04.02.01

Trejo, D., I. Barois, W. Sangabriel-Conde, 2016. Disturbance and land use effect on functional diversity of the arbuscular mycorrhizal fungi. Agroforestry Systems 90: 265-279. Doi: 10.1007/ s10457-015-9852-4

Varela, L., L.V. Hernández-Cuevas, E. Chimal-Sánchez, N.M. Montaño, 2019. Diversidad taxonómica de hongos micorrizógenos arbusculares citados en México. In: Álvarez-Sánchez, F.J., P. Rodríguez-Guzmán, A. Alarcón (eds.), Biodiversidad de microorganismos en México. Importancia, aplicación y conservación. UNAM, Ciudad de México. Pp. 104-155.

Veiga, R., J. Jansa, E. Frossard, M.G.A. Van der Heijden, 2011. Can arbuscular mycorrhizal fungi reduce agricultural weeds? PLOS ONE 6: e27825. Doi: 10.1371/journal.pone.0027825

Wang B., Y.L. Qiu, 2006. Phylogenetic distribution and evolution of mycorrhizas in land plants. Mycorrhiza 16: 299-363. Doi: 10.1007/s00572-005-0033-6

Wang, M., L. Hu, W. Wang, S. Liu, M. Li, R. Liu, 2009. Influence of long-term fixed fertilization on diversity of arbuscular mycorrhizal fungi. Pedosphere 19: 663-672. Doi: 10.1016/S10020160(09)60161-2

Wang, X.X., W. van der Werf, Y. Yu, E. Hoffland, G. Feng, T.W. Kuyper, 2020. Field performance of different maize varieties in growth cores at natural and reduced mycorrhizal colonization: yield gains and possible fertilizer savings in relation to phosphorus application. Plant Soil 450: 613-624. Doi: 10.1007/s11104020-04524-1

White, T.J., T. Bruns, S. Lee, J. Taylor, 1990. Amplification and direct sequencing of fungal ribosomal RNA for phylogenetics. In: Innis, M.A., D.H. Gelfand, J.J. Sninsky (eds.), PCR protocols: a guide to methods and applications. Academic Press, Cambridge. Pp. 315-322. Doi: 10.1016/B978-0-12-372180-8.50042-1 
Yao, Q., X. Li, G. Feng, P. Christie, 2001. Mobilization of sparingly soluble inorganic phosphates by the external mycelium of an arbuscular mycorrhizal fungus. Plant and Soil 230: 279-285. Doi: 10.1023/A:1010367501363

Zhang, R., Y. Mu, X. Li, S. Li, P. Sang, X. Wang, H. Wu, N. Xu, 2020. Response of the arbuscular mycorrhizal fungi diversity and com- munity in maize and soybean rhizosphere soil and roots to intercropping systems with different nitrogen application rates. Science of the Total Environment 740: 139810. Doi: 10.1016/j. scitotenv.2020.139810 